\title{
SPATIAL PRICE AGGREGATION, ITEM WEIGHT AND CONSTANT UTILITY*
}

\author{
James C. Simmons and Elihu Schneider**
}

Early attempts at measuring consumer price changes had welfare or utility concepts in mind. The purpose was to determine, through price changes, whether the welfare of certain classes of people, usually the working class, was improving or deteriorating. This usually was done by pricing at different times a list of items commonly consumed by workers. These measures of price change were referred to as changes in the "cost of living."

As the conceptual and statistical sophistication of the producers of such measures increased, there was a greater interest in exactly what was being measured and what was meant by the term "cost of living" (Mitchell, 1939). It was recognized very early that the term "cost of living" had meaning only in the context of a homogeneous group of people consuming the same items over time and having a constant income level. Given these constraints, changes in the prices of the items would indicate changes in welfare.

The problem was that groups of people are not homogenous as to consumption patterns and incomes (Ulmer, 1950) and could not have the same "costs of living" or cost of living changes with given changes in prices. It was obvious that under the circumstances any cost of living index would have very little validity for measuring spatial or temporal differences in living costs. The assumption of constant marginal utility is invoked here. "Baskets" of goods and services, differing spatially, are claimed to yield the same welfare or utility to a class or category of people consuming them. In other words, constant utility on the part of the consumers is assumed. This assumption is merely a mental exercise required to remove conceptual problems; it does not improve the validity of the measures compared. The reasoning is sophisticated in two ways: first, in the sense of being appealing intellectually, and second, in the original sense of sophistry. Facing the impractical task of seeking the ideal groups required for a "cost of living index," one asserts that income and tastes are so closely related that income is a surrogate for taste. Therefore, if people have the same tastes, they receive equal utilities from consumption with their equal incomes. From this approach the development of consumer price indices for the "working classes,"

* Comments by Dr. Gary M. Foumier on a draft of this article are acknowledged and appreciated.

**Associate professor of economics, Florida State University; and economist, Florida Department of Revenue. "poverty level" groups, and "low income classes," occurred. Such indexes were thought to measure the "cost of living" of the various groups.

Although current price indices are not "cost of living" indices in the sense once used (i.e., relating to the cost of a specific standard or level of living of a specific group of people), assumptions about the utility of consumers have lingered, giving rise to criticism. Ulmer clearly states that there is no place for non-verifiable assumptions about utility in the construction of price indices. Moreover, measures of cost of living have depended on defining the narrow standard or level of living that is to be priced. This always has been an arbitrary or judgmental process, and if comparisons were to be made spatially or temporally with baskets of varying items and weights, it was necessary to assume equality of something. To the economist the assumption of equal "satisfaction" or constant utility was acceptable (Sherwood, 1975; Bureau of Labor Statistics, 1971). To avoid the indeterminacy of relying on assumptions, there has been movement toward the use of price indices based on actual expenditure surveys of target populations as to points of purchase and the prices of representative items of consumption.

There is no place in a pure price level index for assumptions of constant utility. A pure price level index measures and reports only price changes. The measurements are statistically explicit. The rates of change in the prices are determined by the base period weights and the specifications of the items priced. Given the expertise of the pricers and the statistical procedures employed, a perfect price index would be error-free. No index is error-free, but the errors can be measured and corrected, while assumptions can neither be measured nor corrected. (Sherwood, 1975).

What is correct for a single locational price index is not necessarily correct when indices are to be compared or when they are to be aggregated spatially. When rates of changes in prices are compared, nothing is implied. Only the numerical difference between ratios is shown. For example, comparing the rate of price change in New York during a specified period of time with the rate of price change in London during the same period reveals only that the reported rate of change, as calculated, for the aggregate average price of the items priced in London was higher, or lower, or the same as in New York. The comparison does 
not indicate what the statistically average Londoner was consuming, what his or her real income was, whether the items were subsidised, or how satisified he or she was compared to his or her counterpart in New York. If identical items had the same fixed weights, and the same statistical procedures were used in both places, any difference in the rates of change in the price indices would indicate average changes in the price of the aggregate items and comparison of the rate of change would become relevant.

When a price index is calculated from an aggregate of samples of item prices taken in various geographical locations, the item selection and the item weights become critical considerations. Currently the items are selected made by the Bureau of Labor Statistics (BLS) Consumer Price Index (CPI) isdeveloped from consumer expenditure surveys in each location (city). With certain exceptions, the basket of items priced is constant across space. If an index is to be published for a location, the local expenditure percentages (relative importances) are used as weights for the aggregation in construction of the local price index. These location specific item expenditure weights (relative importances) are used in aggregating the item prices spatially.

The national CPI published by BLS is composed of weighted price data from various parts of the country. The question raised in this article is this: What item weights should be used in aggregating the item prices (price changes) in each geographic location? The primary consideration is to eliminate all changes in the aggregate index that do not result from changes in item prices. For this purpose an identical basket of goods must be priced in all locations and identical fixed base period expenditure weights must be employed. In each instance concern is with statistical identity so that price relatives are not influenced.

If the statistically average consumer purchases the base period fixed weight basket of goods and services, he or she will be faced with the price changes indicated by the index. If the basket of goods and services is the same for all geographic locations, the local price changes will show the relative changes in the purchasing power of average consumers in the different geographic locations. If the items in the basket and their weights vary by location it is not possible to make meaningful comparisons of the price changes. Making comparisons, entails making assumptions about utility. One such assumption is that whatever the consumption pattern of the statistically average consumer is, in the various locations, the consumers enjoy the same satisfaction and the consumption patterns in these locations do not change from the base period. Relative price changes under this assumption indicate the changing cost of the same consumption satisfaction. This type of comparison also requires a narrowly defined social and income group. Thus, the index becomes a "cost of living" index rather than a pure price level index. A cost of living index based on the constant utility assumption permits not only the patterns of consumption of items vary but the basket of items to be different because the assumption, like the wand of a fairy, creates an illusion of equality that does not exist.

It may be safe to say that consumers in each location will attempt to maximize their total utility or satisfaction through varying their consumption patterns when there is a relative change in item prices, but it is entirely unreasonable to assume that they maintain constant utility through these adjustments when there are differential price changes geographically, that change the purchasing power of incomes, because income changes are not necessarily in the same proportion as the price changes.

In order to aggregate item prices across geographic locations it is essential that the items whose prices are being aggregated be the same or close enough not to influence prices. This problem is not addressed here. While the items for the CPI could be closer to identical, the argument in this article is that the weights of the items should be identical for all locations rather than having unique location weights.

The purpose of a temporal price index such as the CPI is to show price change over time for a fixed basket of goods and services. This computation is a statistical exercise. It is quantitative, not subjective. Concern about the utility consumers derive from their consumption of the items in the basket of goods and services is irrelevant. The only question of interest is whether there has been a change in the prices of the items. All consumers might have the same utility or might all have different utilities from the items purchased. Even though the changing prices may reflect changing utilities, attitudes, fads, and scarcities, the price index measures only the price change, not its cause. If any unquantifiable assumptions are allowed to creep into the pricing and statistical procedure for a price index the interpretation becomes indeterminate. It is easy to imagine a price index being adjusted downward by some amount simply because someone thinks that the utility of the goods and services has increased.

It should be obvious that it would be meaningless to aggregate the prices of unlike items to form one index from two. It is for this reason that the BLS, to all intents and purposes, uses approximately the same list of items in all locations for the price survey. The BLS is very careful to insure that the physical and qualitative characteristics of items are the same in all locations. They make no assumption about the utility of items for consumers, although they use different location-specific item weights or "relative 
importances." This article proposes to demonstrate some of the effects of this practice.

Some effects of estimating price change rates using two different rules when aggregating price data spatially are reported below. The usual practice is to use area specific expenditure weights, as for the CPI. This practice is compared to one using the same expenditure weights in all geographic areas (i.e., employing constant expenditure weights across areas). The price data used are from the Florida Temporal Price Index and the Florida Price Level Index. For this article price data for the years 1980, 1981, 1982, and 1983 were selected. These data were used in calculating a CPI-type price index, the FTPI. (This was reported in May 1984 at the Southem Regional Science Association meeting in Orlando.) The FTPI items and prices are available separately for all 67 counties of Florida or for any combination of these counties. The same list of items and the same weights were used in all counties. This basket of items and their weights were used by the BLS for the Miami CPI.

The index comparisons are shown in Table 1. The price data are collected once each year for the preparation of the FPLI, an annual spatial price index comparing price level differences between the counties of Florida. For this purpose, there is no necessity to price the same basket of items from year to year. In practice, most items are priced sequentially for convenience, yet there can be many item changes over several years.

It was possible to have comparable baskets in 1980 and 1981, but not between 1981 and 1982 . It also was possible to have comparable baskets for 1982 and 1983, and between 1983 and 1984, but because of item changes 1984 could not be tied to the 1982 base; therefore, three two-year periods are shown. Making an index series over more years would have required reducing the number of items used considerably. This would have reduced the comprehensiveness of the index and thus, was undesirable.

The indices were calculated with area specific relative importances (RIs) for different population groupings in order to examine the effect(s) of using unique weights for the different areas. Indices were calculated for the state and for county groupings in Florida based on population and corresponding to the BLS RIs A, B, C, and D for the Southeast (see Appendix).

As the items and prices of items used in this study are the same where comparisons are made for specific annual changes in the index, the only factor contributing to the differences in the percentage change in the price index is the relative importances i.e., weights.

Which index is superior? Obviously, a price index based on prices of more or less identical items and expenditure weights is superior. The concept is clear. There is no need to involve the assumption of constant utility for the consumption of unlike things. The index comparisons are shown in Table 1.

Is there any rationale for considering a spatially constant weight index with identical items preferable to a differentially weighted index with item differentials when aggregating spatially or for interremporal comparison? In comparing rates of price changes spatially between locations or comparisons of rates of price change over time, investigators can be confident that the observed rate differentials are due to actual price changes, if they use constant weights and identical items. The rationale is that it is desirable to have unambiguous measures of changes in price alone. For this purpose, constant weights are required.

\section{References}

Mitchell, Wesley C. The Making and Using of Index Numbers. Bulletin No. 656. Washington, D.C.: U.S. Department of Labor, Bureau of Labor Statistics, 1939.

Sherwood, Mark K. "Family Budgets and Geographic Differences in Price Levels." Monthly Labor Review. (April 1975).

Ulmer, Melville J. The Economic Theory of Cost of Living Index Numbers. New York: Columbia University Press, 1950.

U.S. Department of Labor, Bureau of Labor Statisitics. Memorandum to "Users of BLS Budgets and Inter-area Living Cost Indexes." Washington, D.C.: Office of the Commissioner of the Bureau of Labor Statistics, December $15,1971$. 
Table 1

Price Indices Based on Different Relative Importances

\begin{tabular}{|c|c|c|c|c|c|c|}
\hline & \multicolumn{2}{|c|}{$\begin{array}{c}\text { November 1980-November } 1981 \\
\text { (base year 1980) }\end{array}$} & \multicolumn{2}{|c|}{$\begin{array}{c}\text { November 1982-November } 1983 \\
\text { (base year 1982) }\end{array}$} & \multicolumn{2}{|c|}{$\begin{array}{c}\text { November 1983-November } 1984 \\
\text { (base year 1983) }\end{array}$} \\
\hline & $\begin{array}{l}\text { Using Miami RIs } \\
\text { (percent change) }\end{array}$ & $\begin{array}{l}\text { Using Unique RIs } \\
\text { (percent change) }\end{array}$ & $\begin{array}{l}\text { Using Miami RIs } \\
\text { (percent change) }\end{array}$ & $\begin{array}{l}\text { Using Unique RIs } \\
\text { (percent change) }\end{array}$ & $\begin{array}{l}\text { Using Miami RIs } \\
\text { (percent change) }\end{array}$ & $\begin{array}{l}\text { Using Unique RIs } \\
\text { (percent change) }\end{array}$ \\
\hline State & 11.85 & 13.12 & 1.88 & 1.89 & 2.8 & 2.75 \\
\hline B & 11.46 & 13.12 & 2.20 & 2.16 & 2.66 & 2.82 \\
\hline C & 11.91 & 13.02 & 1.44 & 1.59 & 2.63 & 2.21 \\
\hline
\end{tabular}

Notes: No index is given for 1981-1982 because of data problems, nor could 1984 be tied to the 1982 base for the same reason.

Numbers in parentheses are the percentage changes in the BLS-CPI for Miami during the same period as published by the BLS.

* Group $A=$ one county with population of $1,250,000$ and over;

Group B $=$ six counties with populations of 385,000 to $1,250,000$;

Group C $=17$ counties with populations of 75,000 to 385,000 ; and

Group $D=43$ counties with populations of 2,500 to 75,000 .

**Dade County, as the only county in the state with a city with population over one million (Miami), is alone. 


\section{Appendix}

The Procedure for the Florida Temporal Price Index

For any given item, aggregated (across counties) weighted price ratios are computed:

$$
\text { WPR }_{i}=\frac{\sum_{j=1}^{\text {NUMOOUNTIES }} \text { CWGHT }_{j} \times \frac{P_{x_{j}}}{P_{1 j}}}{\sum_{j=1}^{\text {NUMOOUNTIES }} \text { CWGHT }_{j}}
$$

where

$$
\begin{aligned}
\text { WPR }_{\mathrm{i}} & =\text { weighted price ratio average for item } \\
& i, \\
\text { NUMCOUNTIES }= & \text { the number of counties (when the } \\
& \text { index for the state is computed, } \\
& \text { all counties in the state must be } \\
& \text { included), } \\
= & \text { price of item } i \text { in county } j \text { in year } T, \\
& =\text { price of item } i \text { in county } j \text { in year }(T- \\
& 1), \text { and } \\
P_{2 i j} & \text { county weights in year }(T-1), \\
P_{1 i j} & \text { corresponding to the dollar volume of } \\
& \text { sales (as reported by the Department } \\
\text { CWGHT } & \text { of Revenue) in each county in that } \\
& \text { year. }
\end{aligned}
$$

Weighted price ratios for individual items are aggregated to compute a general price index for the state or any group of counties:

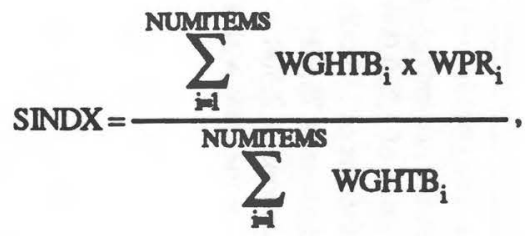

where

$$
\begin{aligned}
& \text { SINDX = price index for the state or any group of } \\
& \text { counties, } \\
& \text { WGHT = is the weight (relative importance) of the } \mathrm{i}^{\text {th }} \text { item for year }(T-1), \text { and } \\
& \text { WGHTB = is the weight of the } \mathrm{i}^{\text {th }} \text { item during the base } \\
& \text { year. }
\end{aligned}
$$

The item weights used were BLS weights for the Miami area.

The BLS published relative importances for the Southeast of the U.S. for the urban areas:
A. population above $1,250,000$,
B. population $385,000-1,250,000$,
C. population $75,000-385,000$, and
D. population $2,500-75,000$.

Since weights for groups A, B, C, and D differ from one another and since all counties in Florida can be classified in one of the four groups, a separate price index could be computed for each group and, in order to calculate an index for the state, the four groups could be aggregated using sales in year $(T-1)$ as relevant weights for the group.

In this case the calculation (equation (1)) is exactly the same as before. Therefore equation (2) becomes:

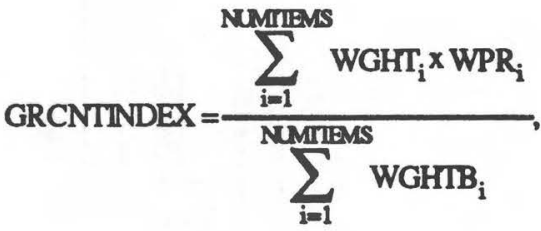

where

GRCNTINDEX = a county group index.

After county group indexes are computed, a state temporal price index can be computed by calculating the weighted average of the group indices as in equation (4) below. The group weighting is determined by the dollar value of sales in each of the groups.

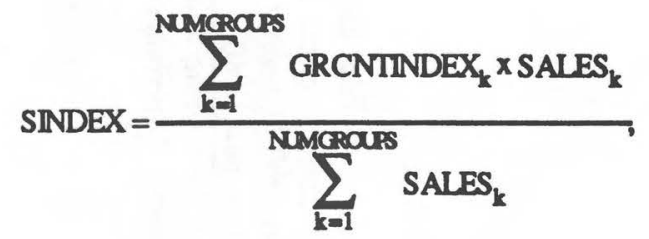

where

$\begin{aligned} \text { SINDEX } & \text { index composed of the aggregation of } \\ & \text { any groups of counties in the state, } \\ \text { NUMGROUPS }= & \text { number of population derived groups } \\ & \text { of counties, } \\ \text { GRCNTINDEX }= & \text { price index for the } k^{\text {th }} \text { group of } \\ & \text { counties, and } \\ \text { SALES } & \text { dollar value of sales in the } \mathbf{k}^{\text {th }} \text { group of } \\ & \text { counties. }\end{aligned}$

